\title{
Challenges encountered diffusing tacit knowledge at Eli Lilly SA
}

\author{
P. Gichuru
}

Eli Lilly (SA) (Pty) Ltd, Johannesburg, South Africa

pauln@lilly.com

\section{P.K.J. Tobin}

Gordon Institute of Business Science, University of Pretoria, Pretoria, South Africa

tobinp@gibs.co.za

\section{Contents}

1. Introduction

1.1 Research problem

2. Benefits of knowledge diffusion

3. Management theories

4. Research methodology

5. Population and sampling

6. Research findings

6.1 Tacit knowledge management context

6.2 Organizational leadership context

6.3 Organizational design context

6.4 Organizational culture context

7. Summary and recommendations

8. References

\section{Introduction}

Eli Lilly SA is the South African affiliate of Eli Lilly and Company, which is a global pharmaceutical company that prides itself in its ability to continuously launch innovative products despite the competitive nature of the healthcare market. To be successful, Eli Lilly, like other pharmaceutical companies, needs talented employees in Research and Development (R\&D) to generate the innovative pharmaceutical molecules. Eli Lilly also needs talented employees in functional areas like Sales and Marketing, Finance, Human Resources, and the Medical department, to name a few, in order to secure demand realization and sustenance of the revenue stream that fuels the R\&D. These personnel have specialized knowledge that is vital in fulfilling their duties and obligations to the company and its shareholders. On the most part, this knowledge resides in the employee's technical skills, analytical ability and years of experience, which makes the knowledge more tacit than explicit. This tacit knowledge that resides in individuals is difficult to quantify in an objective manner and it is highly mobile. In discussions with senior and middle managers, it 
was realized that the company faced the challenge of attracting and retaining talent as well as diffusing knowledge from talented people into the company.

\subsection{Research problem}

Tacit knowledge is personal, context specific and therefore hard to formalize and communicate (Botha 2002:141) To unleash the full potential of tacit knowledge in its employees, there is a need for the company to diffuse this knowledge and have it available to as many of its employees as necessary. However, due to the nature of tacit knowledge, efforts to diffuse it come with distinct challenges. These challenges have been identified by previous work done by Polanyi (cited in Tobin 2003 b), Nonaka (1991) and Haldin-Herrgard (2000). The research objective was to identify the challenges of tacit knowledge diffusion that were most relevant and important to Eli Lilly SA, rank them in order of importance and make recommendations thereof.

A deeper understanding of internalization and diffusion of tacit knowledge has to be obtained for Eli Lilly SA to unleash the resources of this tacit knowledge (Haldin-Herrgard 2000). Cummings and Worley (2001) show that organizational learning can happen at individual or organizational level. Snyder, as cited in Cummings and Worley (2001:518), proposes the integration of both levels of learning. Snyder asserts that learning is organizational to the extent that it achieves organizational objectives, is shared amongst organizational members and learning outcomes are embedded in the organization's systems, structures and culture. It is possible for individuals in an organization to learn while the organization doesn't and vice versa. Because tacit knowledge (in individuals) is difficult to codify, attention has to be directed at how such knowledge can be shared informally across members and organizational units.

Tacit knowledge sharing and diffusion comes with some specific challenges, which include (Beer and Spector 1993; Bradach 1996; Haldin-Herrgard 2000; Nonaka 1991):

- Perception and language

- Time constraints

- Value perception

- Challenges of distance

- Leadership endorsement

- Type of networks

- Company communication structure

- Style of management.

Other challenges include (Cummings and Worley 2001; Ivancevich and Matteson 2002):

- Nature of linkages between units

- Nature of the hierarchy

- Type of systems

- Type of structure

- Shared values

- Skills of managers

- Style of management

- Nature of employee empowerment

- Team dynamics

- Organizational culture. 


\section{Benefits of knowledge diffusion}

Skyrme (2000) gives examples of organizations that have benefited from knowledge initiatives:

BP Amoco has used virtual team working and video conferencing to facilitate faster resolution to customer problems. BP also adapted from the US army the 'after action reviews' a process that involved finding what was supposed to happen, what actually happened, why there was a difference and the learnings from this. According to Cummings and Worley (2001), in 1999, two years after the start of BP knowledge management projects, documented savings were US\$260 million with another US\$400 million anticipated.

Texas instruments instituted best practice sharing between semiconductor fabrication plants resulting in over US\$ 500 million savings.

Buckman laboratories created knowledge networks that connected frontline employees with expertise throughout the company, which has helped create innovative solutions to customer problems.

There are established economic and competitive advantages for companies that aim for knowledge leadership. The 2002 global MAKE report (Chase 2002) is quite emphatic about these advantages, as the quote below from finalists of the most admired knowledge enterprises (MAKE) will show;

'The 2002 Global MAKE Finalists and Winners trading on the NYSE/NASDAQ showed a Total Return to Investors (TRS) for the period 1991-2001 of 25.8\% - a staggering 3.2 times the Fortune 500 median. Global MAKE leaders in TRS for this period were: Dell Computers (58.8), Best Buy (49.1), Cisco Systems (44.4) and Oracle (44.1).

'Another key metric is Return on Capital Expended (ROCE). The 2002 Global MAKE Winners showed an average ROCE of 29.2 - compared to the Global Fortune 500 average of 17.4. Unilever led in this metric with 123.5, followed by Nokia (46.6), Microsoft (33.1) and Royal Dutch/Shell (29.0).

'Finally, profits as a percentage of assets for the publicly traded 2002 Global MAKE Winners were 7.9 - over four times that of the average Global Fortune 500 company. Leaders in this metric were Nokia (19.5), Microsoft (18.1) and Siemens (11.9). Whether the metric is TSR, ROCE or profits as a percentage of assets, the 2002 Global MAKE Finalists and Winners clearly demonstrate that knowledge pays!'

From the examples given, the authors argue that it is no longer in question if an organization should leverage on its internal and external knowledge. The question is how to do this.

\section{Management theories}

Knowledge management theory is one of the bodies of knowledge that the authors referred to extensively. For the purposes of this research, the authors adopted the Penguin definition of knowledge, that is 'Information, understanding and skills acquired through learning or experience', because it encompasses both tacit and explicit knowledge (Allen 2000). Two main types of knowledge have been distinguished, explicit and tacit (Nonaka 1991; O’Hagan 
and Green 2002). Explicit knowledge can be easily encoded, explained and understood while tacit knowledge is highly subjective and personal, making it difficult to formalize and write down. Knowledge management focuses on how knowledge can be organized and used to improve organizational performance (Cummings and Worley 2001:515). From a knowledge management perspective, tacit knowledge sharing and diffusion comes with its own different challenges; it is invisible and hard to express. Secondly, epitomes of tacit knowledge in the working environment are fuzzy things like intuition, rule-of-thumb, gut feeling and personal skill. Thirdly, tacit knowledge cannot be given in lectures, found in databases, textbooks, manuals or internal newsletters for diffusion. Fourthly, tacit knowledge is deeply rooted in action and individual commitment aspects that are rather difficult to transfer (Nonaka 1991). Haldin-Herrgard goes to some lengths to bring out the difficulties in sharing specifically tacit knowledge - difficulties relating to perception and knowledge, time constraints, value perception and distance.

Organization design theory was the second management theory used in this research. Goold (Goold and Campbell 2002) has suggested some good organization design principles that are likely to foster a knowledge-sharing environment. These include specialization and coordination among other things. On coordination, Goold describes ways in which organizations can have good linkages between units. Important in knowledge diffusion is the shared know-how links, which involves best practice sharing and the leveraging of expertise among different functional areas. Beer and Spector (1993) have used five of the 7-S model (originally presented by Waterman, Peters and Phillips 1980): Structure is not organization. Business Horizons describe factors that enhance organization learning . Using this model the organization design should have systems that facilitate acquisition, processing and sharing of information, a structure that encourages interdependency between units, the right level of skills to manage within and across teams, a style of management that is not individualistic and punishing, and shared values.

Organizational leadership theory was the third management theory that was used by the author. Leaders in learning organizations model openness, risk taking and reflection necessary for learning (Cummings and Worley 2001). The organizational leaders have to be brave enough to confront the status quo and inspire others. Leaders in these organizations endeavour to create high performing teams. It is the leader's role to adequately empower members of such teams so that they can trust each other and their leader too. On empowerment, legitimate power (authority) (Ivancevich and Matteson 2002) is an important consideration when analysing the propensity to share knowledge. Another form of power is expert power (Ivancevich and Matteson 2002) where the expert is sought for his or her unique skills and knowledge. Of interest to the authors are the challenges of sharing expert knowledge. Beaty (2003) asserts that knowledge transfer in a team is easier when the team members trust each other. According to Beaty (2003), trust in a team is built by communication, support, respect, fairness, predictability and competence.

Organizational culture theory was the final management theory that the authors referred to. The authors propose that the propensity of employees to share knowledge in an organization is dependent on the organizational cultural orientation. Snyder as cited in Cummings and Worley (2001) supports this view in his model of how organizational learning affects organizational performance (Cummings and Worley 2001:518). The authors thus find Hofstede's cultural dimensions appropriate to study Eli Lilly SA's cultural orientation towards knowledge diffusion. Hatch (1997) reviews Hofstede's work, which proposes that national cultures are manifested in organizations, and he puts forward four dimensions, namely power distance, uncertainty avoidance, individualism versus collectivism and masculinity.

The authors tested Eli Lilly SA's orientation to these four dimensions in order to determine 
the company employees’ propensity to share knowledge.

\section{Research methodology}

The authors used a cross-sectional research method based on mainly deductive as well as inductive approaches. The inductive approach attempted to define the level of perception of the problem (i.e. tacit knowledge diffusion), the magnitude of the problem and the major reasons for the problem. The deductive approach was the main research method whose aim was to identify relationships by the use of a survey that spanned right though the organizational hierarchy [senior managers (10), line managers (24), non-line managers (24), administration staff (22), sales representatives (74)]. Via a structured questionnaire, it was attempted to identify the challenges that Eli Lilly SA faced in tacit knowledge diffusion and from the findings thereof, rank them and make recommendations. The survey through a questionnaire was favoured because of the deductive approach, large amounts of data could be collected economically, the data could be standardized, allowing for comparison. Also due to the time constraints of the research, questionnaires allowed for the responses to be quantified and easily summarized. The self-administered questionnaire was designed from the four contexts, namely tacit knowledge management, organizational design, organizational culture and leadership. From each context, the literature suggested important aspects to be fulfilled for tacit knowledge diffusion to occur.

The questionnaire consisted of questions that established certain constant variables such as the respondent's names (optional), position in company and years of experience in that position, department and qualification. The authors did not ask for demographic data such as age and sex as these had little bearing to the research.

There were questions aimed at establishing internal agreement, that is, the respondents' opinion of tacit knowledge diffusion and its importance in the organization for attaining its objectives. There were questions to test the various hypotheses in the contexts of tacit knowledge management, organizational design, organizational leadership and organizational culture.

The following attributes were borne in mind in the design of the questionnaire:

- All the respondents were computer literate and had access to e-mail through Lotus Notes provided by Eli Lilly SA.

- The confidence that the right person would receive the questionnaire was high.

- The likelihood of contamination and/or distortion of the data was very low.

- The population of respondents were geographically dispersed (the questionnaire was sent to everybody who was on Eli Lilly SA e-mail list).

- The expected response rate from e-mailed questionnaire was 30\% (Saunders, Lewis and Thornhill 2003:281).

- The responses were sent back via e-mail and collated automatically using the Eli Lilly SA Lotus Notes based surveyor tool.

The demographical and internal agreement questions aside, a four point Likert-style rating scale ('strongly agree', 'agree', 'disagree', 'strongly disagree') was used in two-thirds of the questions, as opposed to a five or six-point scale so as not to allow the respondents to remain undecided (Saunders et al . 2003:296).

This method had some limitations. Use of the questionnaire was non-empathetic since the responses were limited to questions asked and there was little opportunity to seek for 
clarification. Questionnaires were also impersonal and employees might have been unwilling to provide honest answers. Questionnaires also elicited biases, for example the respondents might have tended to answer questions in a socially acceptable manner. Ultimately, this might have put the validity of the conclusions in question (Cummings and Worley 2001:116).

\section{Population and sampling}

Probability sampling was used where the chances for each respondent being selected was the same. The authors opted to collect data from the entire population of Eli Lilly SA's employees (154). Identification of the sampling frame (i.e. list of all the cases in the populations) was done using the Eli Lilly SA e-mailing list. Everyone on the list was included.

\section{Data analysis}

Responses from questions on the demographic data (questions 1-5) were collected as is and categorized. Answers to these questions were used as the constants. Questions 6 and 7 had only two options as answers of which 'yes' and 'important' were assigned a score of 1 while the answers 'no' and 'not important' were assigned a score of zero. The cut-off point was a mean score of 0,5 .

Question 8 had a four-point Likert scale of 'very good', 'good', 'bad' and 'very bad'; 'very good' had a score of 4 while 'very bad' had a score of 1 . All the responses of 'very good' and 'good' were clustered together and the same for those of 'bad' and 'very bad'. A mean score of 2,5 was considered the cut-off.

Questions 9-30, with question 14 as an exception, all had a four-point Likert scale ('strongly agree', 'agree', 'disagree', 'strongly disagree') where 'strongly agree' received a score of 4 and 'strongly disagree' a score of 1 . 'Strongly agree' and 'agree' were clustered together and the same was done for 'disagree' and 'strongly disagree'. A mean score of 2,5 was used as a cutoff point.

As for question 14, the four options were 'face-to-face', 'e-mail', 'telephone' and 'voice-mail'. 'Face-to-face' received a score of 1 while all the rest had a score of zero. The cut-off point was a mean score of 0,5 . The questions and responses are outlined in Table 1.

Table 1 Questions and responses

\begin{tabular}{|c|c|c|c|}
\hline Number & Question & Median score & $\begin{array}{l}\text { Overall } \\
\text { result }\end{array}$ \\
\hline \multicolumn{4}{|c|}{ Tacit knowledge management } \\
\hline 6 & $\begin{array}{l}\text { I believe that tacit knowledge management } \\
\text { is important for competitive advantage }\end{array}$ & 1 & Yes \\
\hline 7 & $\begin{array}{l}\text { I believe that tacit knowledge management } \\
\text { diffusion is important }\end{array}$ & 1 & Important \\
\hline 8 & $\begin{array}{l}\text { Eli Lilly SA does a good job internalizing } \\
\text { tacit knowledge }\end{array}$ & 3 & Good \\
\hline 9 & $\begin{array}{l}\text { I often find it hard to fully express myself } \\
\text { in words when sharing my thoughts and }\end{array}$ & 3 & Disagree \\
\hline
\end{tabular}




\begin{tabular}{|c|c|c|c|}
\hline & |ideas with my colleagues & & \\
\hline 10 & $\begin{array}{l}\text { I have ample time and opportunity to } \\
\text { reflect on tacit knowledge gained }\end{array}$ & 3 & Agree \\
\hline 11 & $\begin{array}{l}\text { I have ample time and opportunity to share } \\
\text { and receive tacit knowledge }\end{array}$ & 2 & Disagree \\
\hline 12 & $\begin{array}{l}\text { My workmates and superiors appreciate } \\
\text { suggestions and ideas that I have based on } \\
\text { my knowledge and expertise even when I } \\
\text { do not have enough information to } \\
\text { substantiate them }\end{array}$ & 3 & Agree \\
\hline 13 & $\begin{array}{l}\text { My workmates readily share information } \\
\text { and expertise, which could help me } \\
\text { improve my performance and enhance my } \\
\text { career }\end{array}$ & 3 & Agree \\
\hline 14 & $\begin{array}{l}\text { I rely heavily on the following media to } \\
\text { interact with persons in the organization } \\
\text { whose knowledge and expertise is } \\
\text { important for my productivity: face-to-face, } \\
\text { email, voicemail, telephone }\end{array}$ & 0 & email \\
\hline \multicolumn{4}{|c|}{ Organizational leadership } \\
\hline 15 & $\begin{array}{l}\text { The leaders in this organization encourage } \\
\text { the sharing of knowledge and expertise } \\
\text { within and between teams }\end{array}$ & 3 & Agree \\
\hline 16 & $\begin{array}{l}\text { I am empowered enough to seek and } \\
\text { acquire knowledge and expertise from } \\
\text { junior members of the organization }\end{array}$ & 3 & Agree \\
\hline 17 & $\begin{array}{l}\text { I am empowered enough to seek and } \\
\text { acquire knowledge and expertise from } \\
\text { senior members of the organization }\end{array}$ & 3 & Agree \\
\hline 18 & $\begin{array}{l}\text { Where I have expert knowledge, I feel } \\
\text { obliged to share my expertise with my } \\
\text { colleagues especially when I know that this } \\
\text { will advance their objectives }\end{array}$ & 3 & Agree \\
\hline 19 & $\begin{array}{l}\text { In my work team, I fully trust all my team } \\
\text { mates, i.e. we communicate freely, offer } \\
\text { and receive support from each other etc. }\end{array}$ & 3 & Agree \\
\hline 20 & $\begin{array}{l}\text { In my work team, I fully trust my team } \\
\text { leader, i.e. we communicate freely with, } \\
\text { offer and receive support him/her etc. }\end{array}$ & 3 & Agree \\
\hline \multicolumn{4}{|c|}{ Organizational design } \\
\hline 21 & $\begin{array}{l}\text { I know exactly who in the organization has } \\
\text { specific know-how and expertise that can } \\
\text { help me in the performance of all aspects of } \\
\text { my duties }\end{array}$ & 3 & Agree \\
\hline 22 & $\begin{array}{l}\text { In this organization, I am rewarded for } \\
\text { assisting my team/division attain its }\end{array}$ & 3 & Agree \\
\hline
\end{tabular}




\begin{tabular}{|c|c|c|c|}
\hline & objective & & \\
\hline 23 & $\begin{array}{l}\text { My manager has the skills to manage both } \\
\text { within my team and across other teams as } \\
\text { well }\end{array}$ & 3 & Agree \\
\hline 24 & $\begin{array}{l}\text { My manager is very keen to punish those } \\
\text { colleagues who are errant }\end{array}$ & 2 & Disagree \\
\hline 25 & $\begin{array}{l}\text { The management in this organization } \\
\text { encourages and rewards individual } \\
\text { achievers who are not team players }\end{array}$ & 3 & Disagree \\
\hline 26 & $\begin{array}{l}\text { When I have important information to } \\
\text { share, I am obliged to pass it to the relevant } \\
\text { person through my immediate manager but } \\
\text { not directly to him/her }\end{array}$ & 3 & Disagree \\
\hline 27 & $\begin{array}{l}\text { My organization is geared towards } \\
\text { independent units/teams }\end{array}$ & 3 & Agree \\
\hline \multicolumn{4}{|c|}{ Organizational culture } \\
\hline 28 & $\begin{array}{l}\text { In my organization, it is accepted that there } \\
\text { be a lot of distance between employees and } \\
\text { senior management }\end{array}$ & 3 & Disagree \\
\hline 29 & $\begin{array}{l}\text { My organization quickly accepts innovative } \\
\text { ideas and eccentric behaviours }\end{array}$ & 2 & Disagree \\
\hline 30 & $\begin{array}{l}\text { In my workplace, the emphasis is on career } \\
\text { advancements and high earnings }\end{array}$ & 2 & Agree \\
\hline
\end{tabular}

\section{Research findings}

Table 2 outlines all the hypotheses that were tested and the results.

Table 2 Hypotheses tested and results

\begin{tabular}{|l|l|l|}
\hline Hypothesis & Description & Accepted/Rejected \\
\hline 1 & $\begin{array}{l}\text { The employees at Eli Lilly SA believe that tacit } \\
\text { knowledge diffusion is important for the } \\
\text { company to gain competitive advantage. }\end{array}$ & Accepted \\
\hline 2 & $\begin{array}{l}\text { Eli Lilly SA does a good job internalizing tacit } \\
\text { knowledge. }\end{array}$ & Accepted \\
\hline 3 & $\begin{array}{l}\text { Perception and language do hinder tacit } \\
\text { knowledge diffusion at Eli Lilly SA. }\end{array}$ & Rejected \\
\hline 4 & $\begin{array}{l}\text { Employees at Eli Lilly SA have ample time and } \\
\text { opportunity to share and receive tacit } \\
\text { knowledge. }\end{array}$ & Rejected \\
\hline 5 & $\begin{array}{l}\text { Tacit knowledge is valued in its most } \\
\text { elementary form, namely intuition. }\end{array}$ & Accepted \\
\hline & &
\end{tabular}




\begin{tabular}{|l|l|l|}
6 & $\begin{array}{l}\text { Face-to-face is the medium most used by Eli } \\
\text { Lilly SA employees to share tacit knowledge } \\
\text { (this hypothesis tested the importance of } \\
\text { distance in tacit knowledge diffusion) }\end{array}$ & Rejected \\
\hline 7 & $\begin{array}{l}\text { The leadership at Eli Lilly SA encourages tacit } \\
\text { knowledge transfer within and between teams. }\end{array}$ & Accepted \\
\hline 8 & $\begin{array}{l}\text { The organizational design at Eli Lilly SA is } \\
\text { supportive of tacit knowledge diffusion. }\end{array}$ & Accepted \\
\hline 9 & $\begin{array}{l}\text { The organizational culture at Eli Lilly SA is not } \\
\text { supportive of tacit knowledge diffusion. }\end{array}$ & Rejected \\
\hline
\end{tabular}

\subsection{Tacitknowledge management context}

There were six hypotheses ( 1 to 6 ) tested under the tacit knowledge management context. Of the respondents, 79 of 80 (99\%) believed that tacit knowledge diffusion was important for the company to gain competitive advantage, an indication of complete internal agreement. It seemed that other than the administration staff and non-line managers, the rest of the respondents were quite comfortable with how the company went about internalizing tacit knowledge. On perception and language, the majority of the respondents disagreed that perception and language hindered tacit knowledge diffusion. On time constraints, even though the majority of employees had ample time to reflect on tacit knowledge gained, they indicated that they did not have the time to share and receive tacit knowledge from their colleagues. On value perception, it was very clear from the results that tacit knowledge is valued organization wide in its most elementary form, that is, intuition. This meant that employees felt that they were adequately heard particularly when they did not have enough data or information to validate claims made. This position was reflected across all the levels of the organization. On the impact of distance, only 35\% of the employee's admitted to using face-to-face as the preferred medium to share tacit knowledge.

\subsection{Organizational leadership context}

Hypothesis 7 provided insight into organizational leadership at Eli Lilly SA. There was unanimous agreement that the leadership at Eli Lilly SA encouraged tacit knowledge sharing within and between teams. On communication, there was also an overwhelming agreement that all the employees across all the categories were empowered to seek knowledge and expertise from junior as well as senior members of the organization.

On support, the majority of the respondents expressed an obligation to share tacit knowledge with their colleagues, especially when they felt that this would advance their colleague's career.

As for respect, fairness, predictability and competence (measures of trust levels), most of the employees also expressed a high degree of trust within their respective teams as well as trust for their team leader.

\subsection{Organizational design context}

Hypothesis 8 provided insight into organizational design at Eli Lilly SA. On specialization, the survey revealed that the majority of the employees seemed confident that they knew the specific people who had expert knowledge. The majority of employees had direct contact with the relevant person when they had to share tacit knowledge A majority of the employees felt that they were rewarded for assisting the team to attain its objectives. On good linkages, a slim majority of the employees reported that Eli Lilly SA was geared towards independent 
teams and units. On skills, the majority of employees (except from administration) expressed the fact that managers had the skills to manage within and across teams. On style of management, all the respondents felt that managers were not keen to punish employees who made mistakes. However, the majority of employees reported that managers encouraged individual achievement to the detriment of the team. Senior managers felt most strongly about this fact, followed by line managers.

\subsection{Organizational culture context}

Hypothesis 9 provided insight into the organizational culture. The majority of employees from all the categories felt that there was low power distance between them and senior management. On uncertainty avoidance, only a minority of the employees felt that innovative ideas and eccentric behaviour were readily accepted in the organization. On whether the culture was masculine or feminine, only a minority of the employees expressed that the culture focused more on career advancements and high earnings, attributes of a masculine culture. Notable were senior managers, administration and representatives who felt otherwise. However, as noted previously, the majority of employees reported that managers encouraged individual achievement to the detriment of the team. Senior managers felt most strongly about this fact, followed by line managers.

\section{Summary and recommendations}

From the analysis of the findings, the following are the most important challenges that Eli Lilly SA faces in order of importance:

- Challenges of distance

- Time constraints.

The analysis of the findings showed that most of the proposed challenges were not relevant to Eli Lilly SA.

Face-to-face interaction is often perceived as a prerequisite for diffusion of tacit knowledge, simply because tacit knowledge is difficult to diffuse technologically, unlike explicit knowledge. This is one reason why Asian companies are spending so much time focusing on face-to-face collaborative knowledge sharing (Chase 2002). O'Hagan supports the challenge of distance when he asserts that because tacit knowledge is highly personal, it is only transferred through face-to-face contact and that shorter distances increase this interaction (O’Hagan and Green 2002)

Tobin (2003 a) asserts that the reality of knowledge management comes when there is sharing, learning and collaboration in the organization. Many Asian companies are already creating environments where the conversion of individual tacit knowledge into corporate knowledge is spurring innovation (Chase 2002).

Thus, the main challenge of distance at Eli Lilly SA does not have a simple solution; a multifaceted approach involving the use of technology to bridge the gap can be used. McKinsey Consulting Firm have used the telephone and voice-mail to transfer tacit knowledge between different branches even across continents with enormous success (Nonaka 1991). BP Amoco has successfully used real-time videoconferencing to transfer tacit knowledge. Eli Lilly SA has videoconference facilities, which need to be used more often.

The other challenge identified was that of time. The current business environment is fast- 
paced and there is little time to reflect on tacit knowledge learned. Therefore, there is even less time to transfer what has been reflected upon to new recruits or colleagues. Reinmoeller (2001) asserts that the importance of time as a context of knowledge management is often neglected

Time is a finite attribute and there are no easy solutions to address this important challenge. Use of mentors at each and every level is bound to increase the contact time between employees. Also, informal gatherings between employees could be encouraged. Employees at all levels should be tasked with reflection at all stages of an on-going project (e.g. before, during and after action learning) with the aim of tangible learnings being drawn and shared with colleagues. It is important for employees to 'spread what they know' (Brown and Duguid 2000)

\section{References}

Allen, R . 2000. New Penguin English dictionary . Durban: Penguin Books.

Beaty, D. 2003.'Leadership’ lectures presented to the MBA 2002/3 class in January 2003, Gordon Institute of Business Science, University of Pretoria. Pretoria: University of Pretoria.

Botha, D.F. 2002.A conceptual framework for the management of knowledge in a knowledge-based enterprise. South African Journal of Business Management 31(4):14-148.

Beer, M. and Spector, B. 1993. Organisational diagnosis: Its role in organisational learning. Journal of Counselling and Development 71:642-648.

Bradach, J. 1996. Organisational alignment: the 7-S model. Harvard Business School publishing (Case study 9-497-045).

Brown, J.S. and Duguid, P. 2000. Balancing act: how to capture knowledge without killing it . Harvard Business Review, May/June:73-80.

Chase, R.L. 2002. Global most admired knowledge enterprises (MAKE) . [Online]. Available WWW: http://www.knowledgebusiness.com (Accessed October 2002).

Cummings, T.G. and Worley, C.G. 2001. Organisational development and change. 7 th ed. New York: Thompson Learning.

Goold, M. and Campbell, A. 2002. Do you have a well-designed organisation? Harvard Business Review, March:17-124.

Hatch, M.J. 1997. Organisational culture; organisational theory. Oxford: Oxford University Press.

Haldin-Herrgard, T. 2000. Difficulties in diffusion of tacit knowledge in organisations. Journal of Intellectual Capital 1(4):357-365.

Ivancevich, J.M. and Matteson, M.T. 2002. Organisation behaviour and management. 6th ed. London: McGraw-Hill.

Nonaka, I. 1991. The knowledge-creating company. Harvard Business Review Nov/Dec:96104 
O’Hagan, S.B. and Green, M.B. 2002. Tacit knowledge transfer via interlocking directorates: a comparison of Canada and the United States . Geografiska Annaler 84(1):49-63.

Reinmoeller, P. 2001. Knowledge management: emphasizing time in space. Unpublished draft submitted to Spacing \& Timing: Rethinking globalisation and standardization . (In print).

Saunders, M., Lewis, P. and Thornhill, A. 2003. Research methods for business students. 3 rd ed. London: Prentice Hall.

Skyrme, D. 2000. Knowledge management assessment. A practical tool from David Skyrme Associates. [Online]. Available WWW: http://www.skyrme.com/kshop/kguides.htm. (Accessed October 2002).

Tobin, P. 2003 a. Information and knowledge management. Lectures presented to the MBA 2002/3 class in January 2003. Gordon Institute of Business Science, University of Pretoria. Pretoria: University of Pretoria.

Tobin, P. 2003 b. The power of story telling. Unpublished MBA thesis, Gordon Institute of Business Science, University of Pretoria. Pretoria: University of Pretoria.

\section{Disclaimer}

Articles published in SAJIM are the opinions of the authors and do not necessarily reflect the opinion of the Editor, Board, Publisher, Webmaster or the Rand Afrikaans University. The user hereby waives any claim he/she/they may have or acquire against the publisher, its suppliers, licensees and sub licensees and indemnifies all said persons from any claims, lawsuits, proceedings, costs, special, incidental, consequential or indirect damages, including damages for loss of profits, loss of business or downtime arising out of or relating to the user's use of the Website.

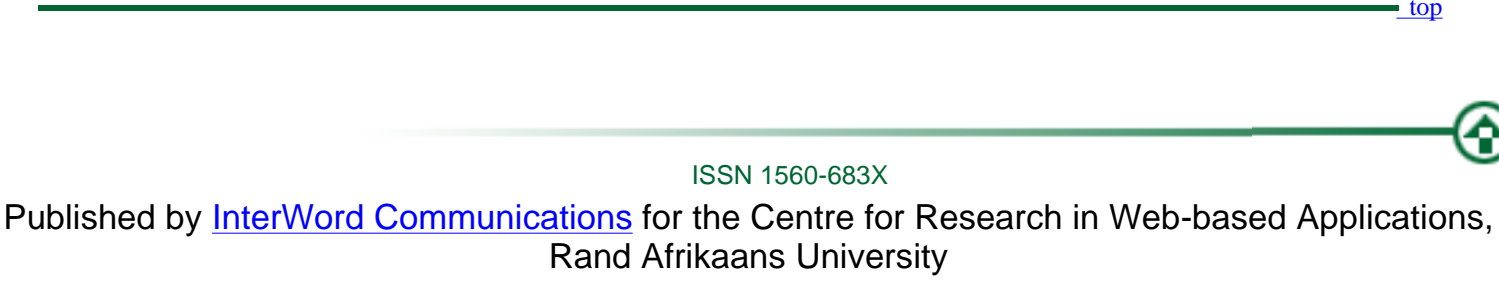

